
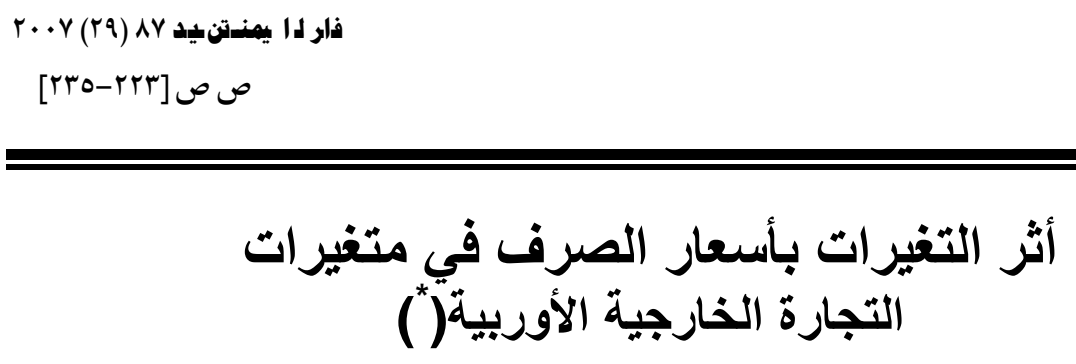

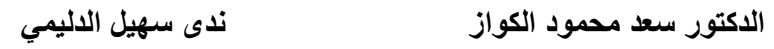

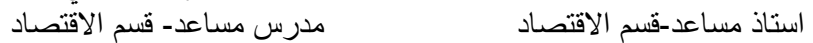

$$
\begin{aligned}
& \text { كلية الادارة والاقتصاد-جامعة الموصل كلية الادارة والاقتصاد-جامعة الموصل }
\end{aligned}
$$

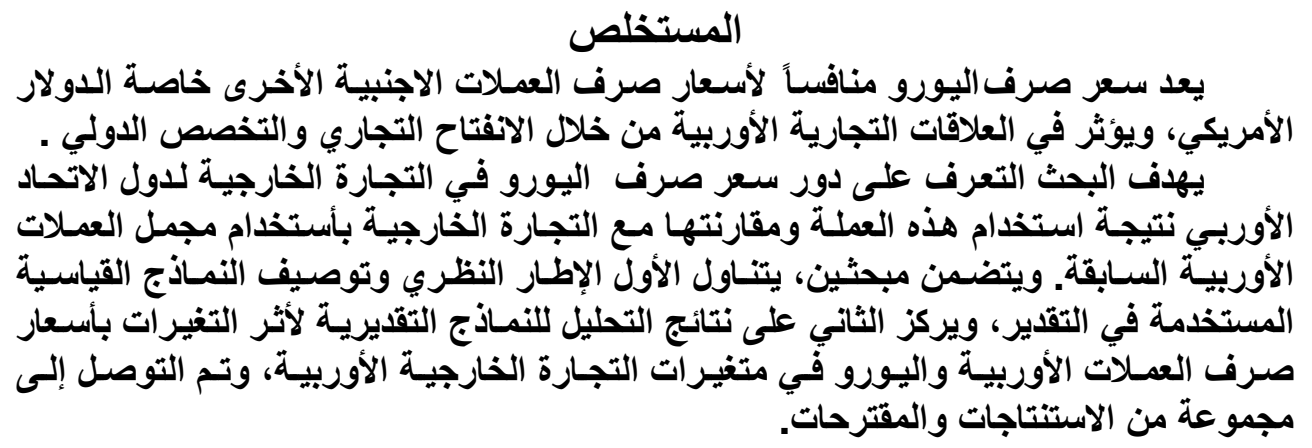

\title{
The Effect of Variations in Exchange Rate of European Foreign Trading Variables
}

\author{
Sa'ad M. Al Kowaz (PhD) \\ Department of Economics \\ University of Mosul
}

\author{
Nada S. Al Doluimi \\ Department of Economics \\ University of Mosul
}

\begin{abstract}
The Euro exchange rate is considered to be a competitive currency of the other currencies exchange rate especially the US dollar. The Euro influences the European commercial interactions by the means of the trading detente and the international specialization.

This research aims at knowing the role of Euro exchange rate in the foreign trade of the European Union as a result of using this currency in comparison with the foreign trade via using gross past European currencies. The research included two chapters, the first one deals with theoretical framework and the description of the relative samples used in the estimation. While, the second chapter focuses on the results of analyzing these samples, the

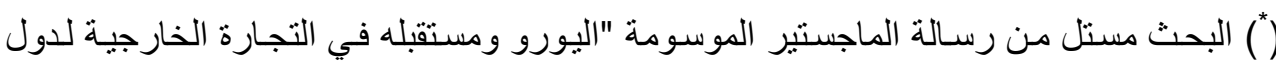

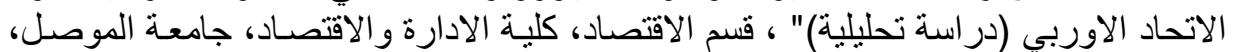

$$
\begin{aligned}
& \text {.... }
\end{aligned}
$$

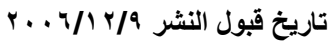

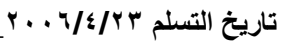


effect of European currencies exchanging and Euro in the foreign trade variables. Finally, many conclusions and suggestions have been demonstrated.

المقدمة

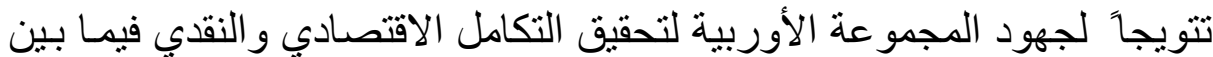

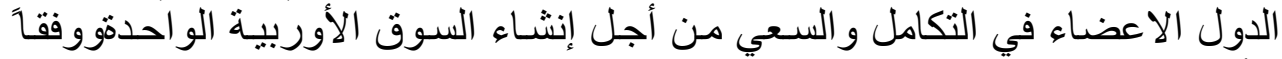

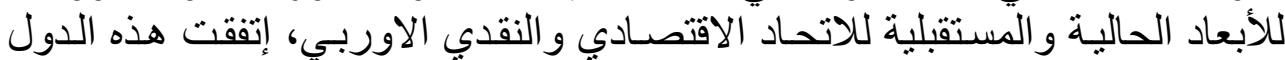

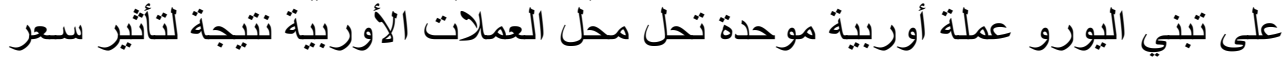

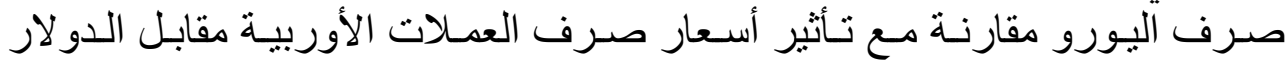

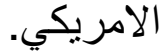

أهمية البحث

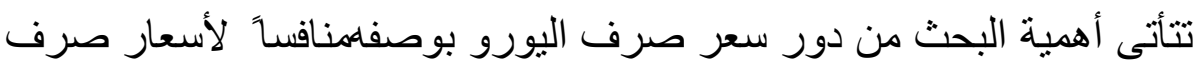

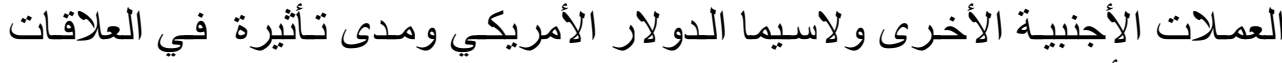

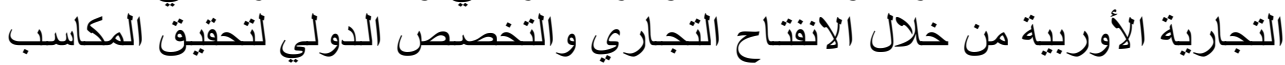
و المنافع من التجارة.

مشكثة البحث

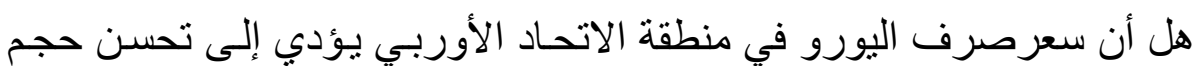

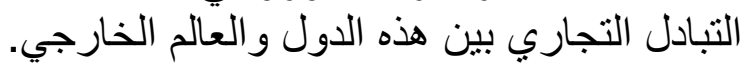

يهدف البحث إلى التعرف على دور سعر صرف اليورو في التجارة الخارجية

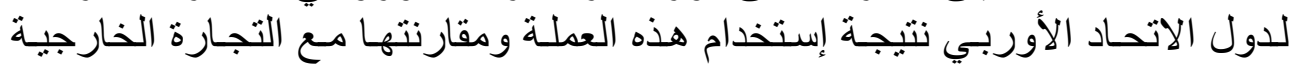
بأستخدام مجمل العملات الأوربية السابقة.

\section{فرضية البحث}

يستند البحث على فرضية مفادها: إن حجم التبادل التجاري سوف يزداد التهاد نتيجة تغير سعر صرف العملات الأوربية باستخدام اليورو بلايً عنها.

\section{منهج البحث}

من أجل الوصول إلى هدف البحث واختبـار فرضيته تم إجر اء در اسـة مقارنـة

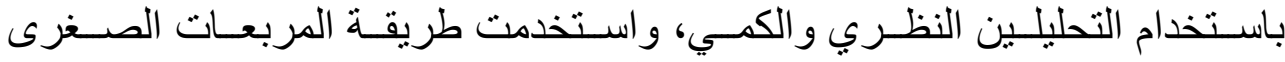

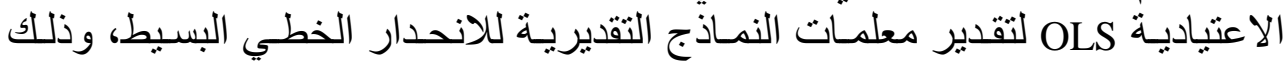
وصـولاً إلى معرفـة مقدار تـأثثير المتغيرات المات المستقلة (العمـلات الأوربيـة و اليورو) 


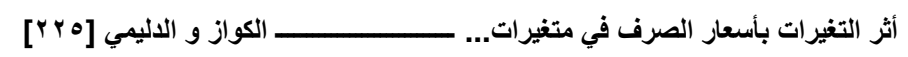

الداخلة في الإنموذج على متغير ات التجارة الخارجية وقد احتسبت أربع صيغ للتقدير

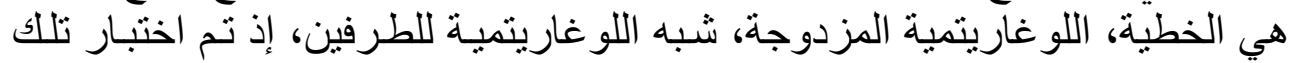
الصيخ واختيار أفضلها و المجتازة للاختبار ات الاقتصادية و الإحصائية و القياسية.

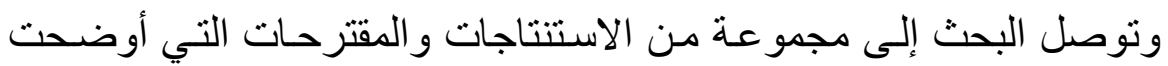

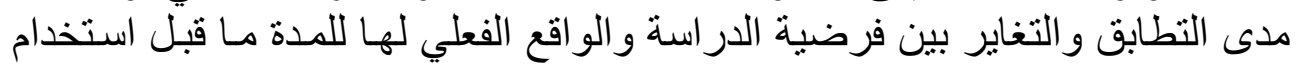
عملة اليورو وما لبعدها.

\section{الإطار النظري وتوصيف النماذج القياسية المستخدمة في التقدير}

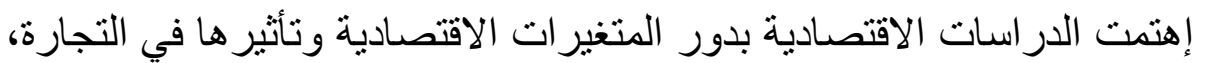

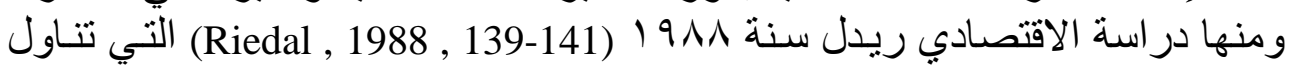

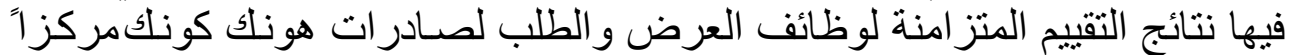

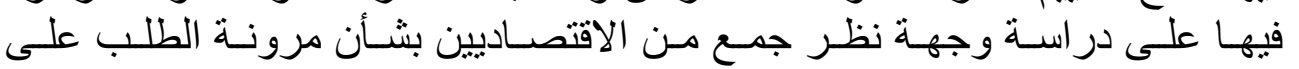

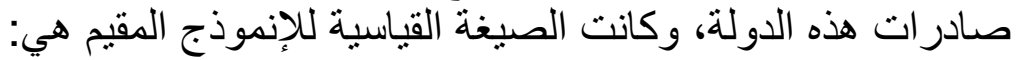

$\mathrm{Q}_{\mathrm{t}}=\mathrm{B}_{0}+\mathrm{B}_{1} \mathrm{P}_{\mathrm{t}}+\mathrm{B}_{2}\left(\mathrm{P}_{\mathrm{t}}{ }^{\mathrm{w}}+\mathrm{Et}\right)+\mathrm{B}_{3} \mathrm{Y}^{\mathrm{w}}{ }_{\mathrm{t}}$.

$\left(\mathrm{B}_{1}<0, \mathrm{~B}_{2}>0, \mathrm{~B}_{3}>0\right)$

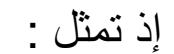

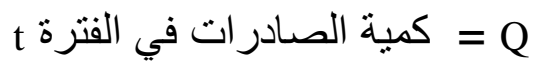
= P = سعر العملة الأجنبية E مستوى فعالية النشاطٌ الاقتصادي للناتج المحلي الإجمالي الحقيقي في أسواق الصادر ات معالئ

= B B $_{1}, B_{2}$

= B3

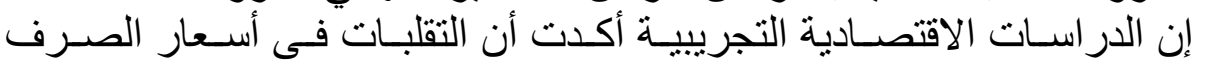

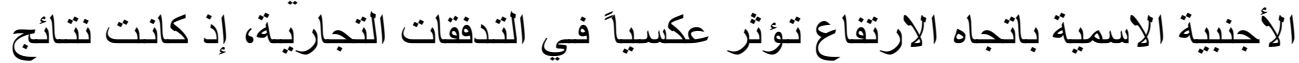

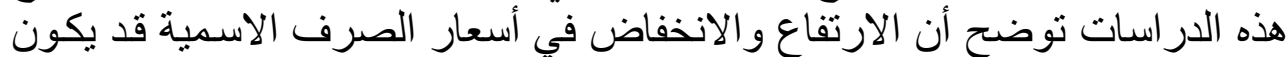

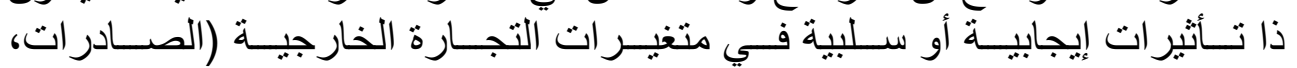

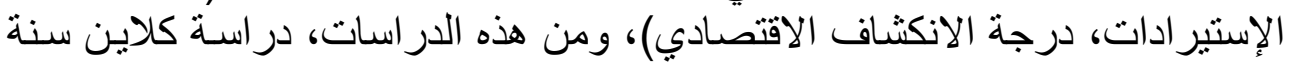

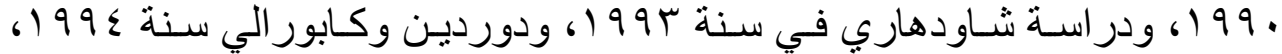

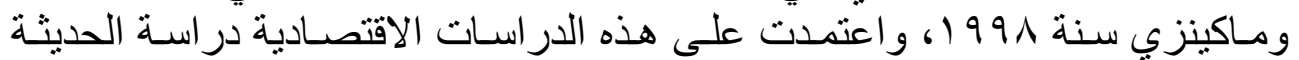

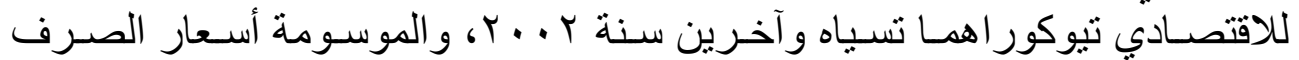

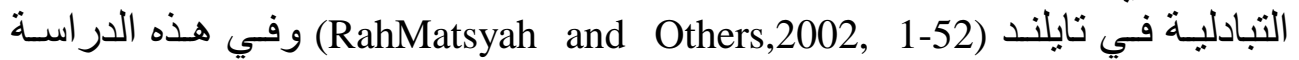

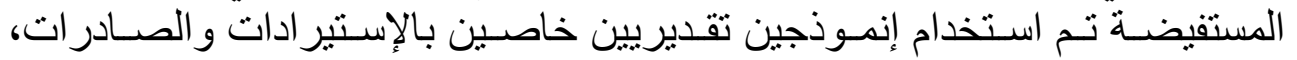

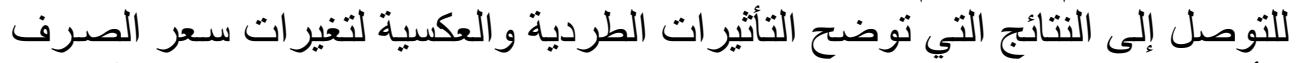

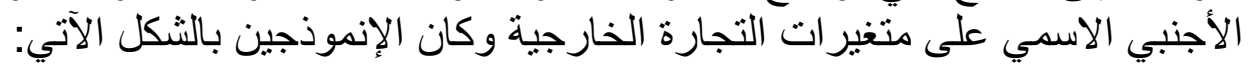




$$
\begin{aligned}
& X_{t}^{u s / J P}=a_{11}+a_{21} y_{t}^{u s / J P}+a_{31} P_{t}^{u s / J P}+a_{41} V_{t}+a_{51} D+E_{11} \\
& M_{t}^{u s / J P}=a_{12}+a_{22} y^{\text {TH }}+a_{32} P_{t}^{\text {us } / J P}+a_{42} V_{t}+a_{52} D+E_{21}
\end{aligned}
$$

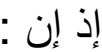

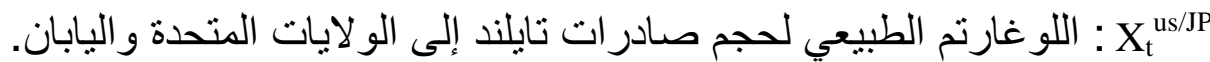

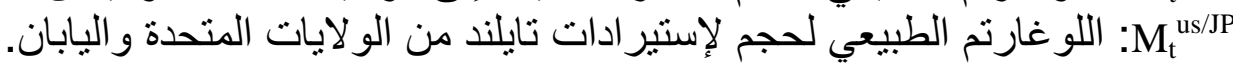

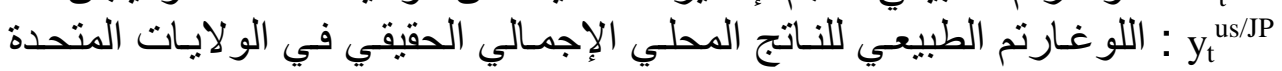
و اليابان. اللو غارتم الطبيعي للناتج المحلي الإجمالي الحقيقي في تايلند.

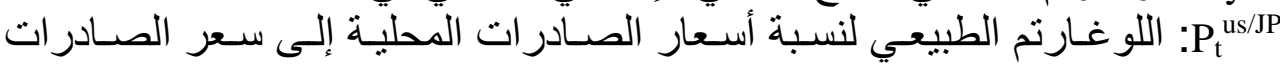

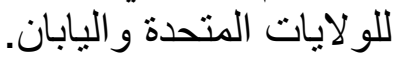

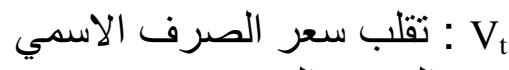

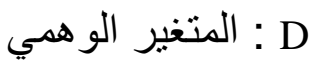

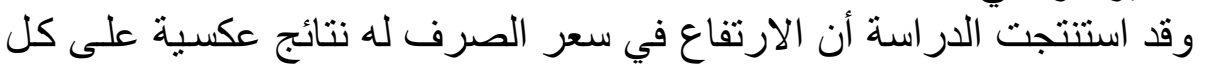

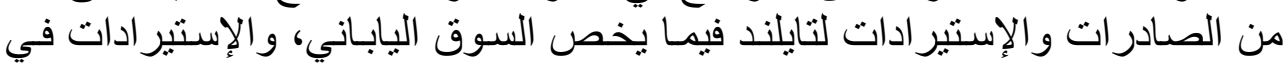

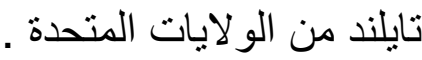

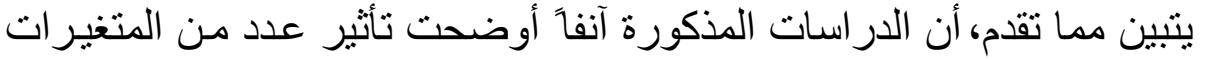

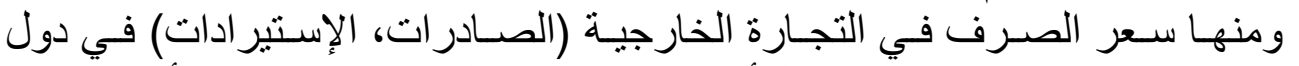

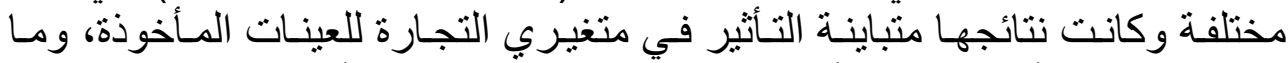

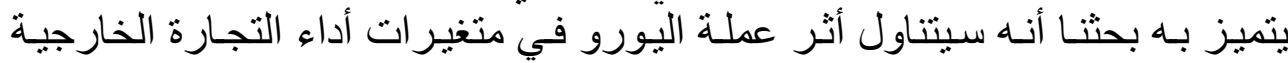

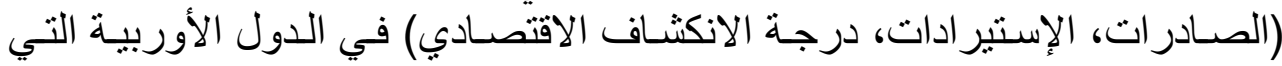

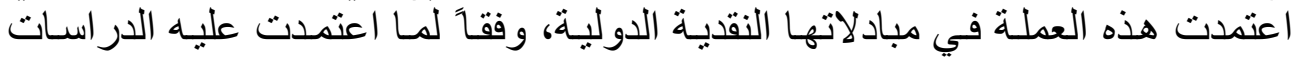

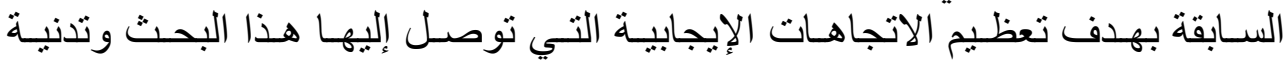

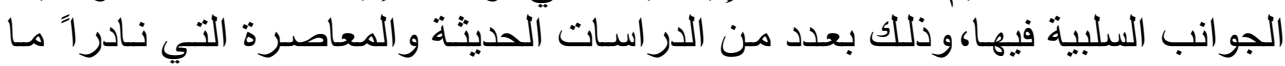

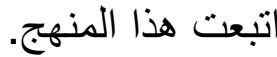

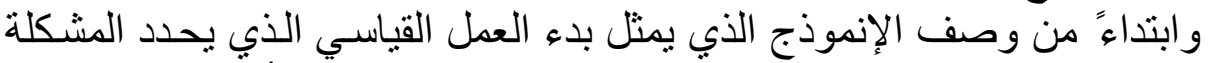

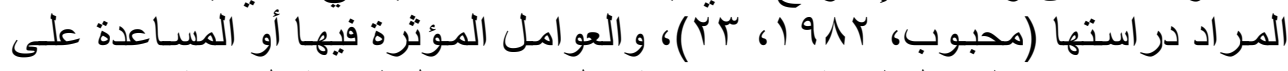

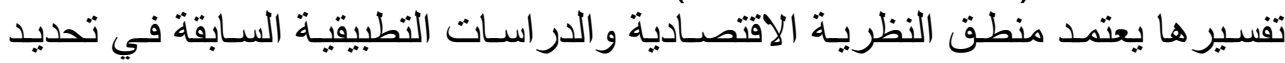

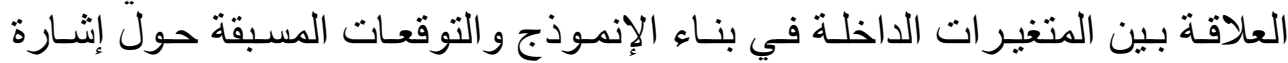

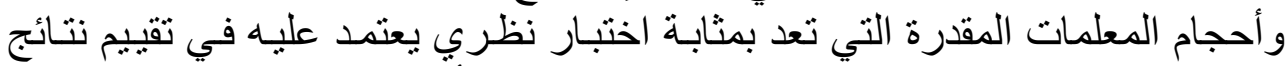

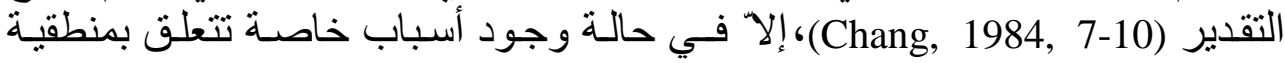
سلوك المتغير الاقتصادي التي توضح هذا الاختلاف عن منطق النظرية الاقتصنادية.

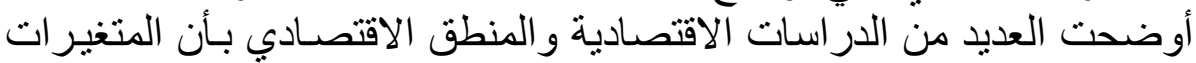

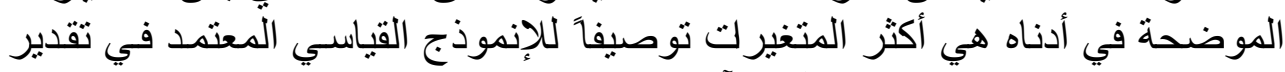
الظاهرة موضو في البناه هي اكثر، وتتمنل بالآتي : 


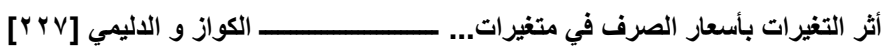

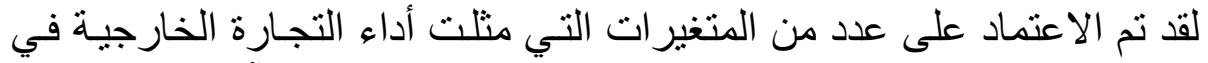

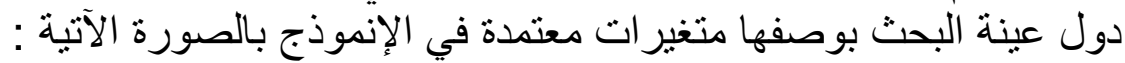
ا ـ نسبة الصادر ات إلى الناتج المحلي الإجمالي.

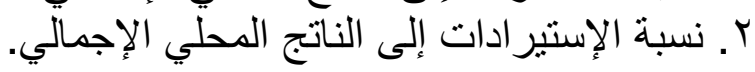
r. درجة الانكثاف الاقتصادي.

$$
\begin{aligned}
& \text { ثانياًَ" ـ المتغير ات المستقلة }
\end{aligned}
$$

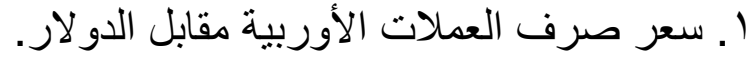

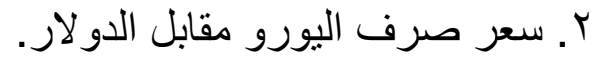

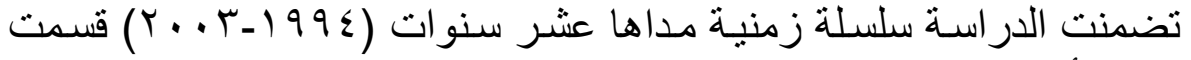

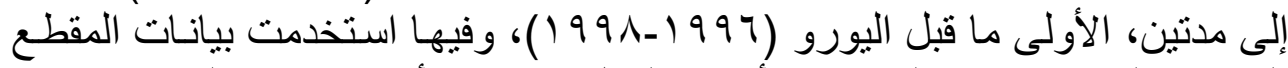

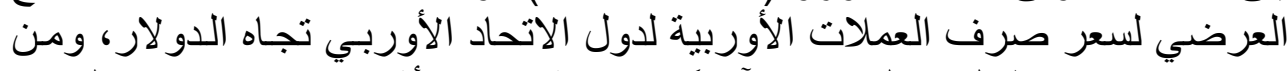

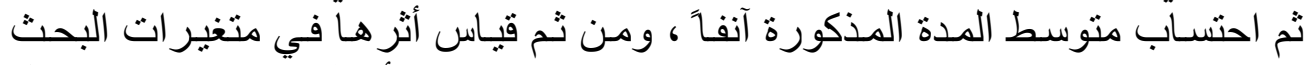

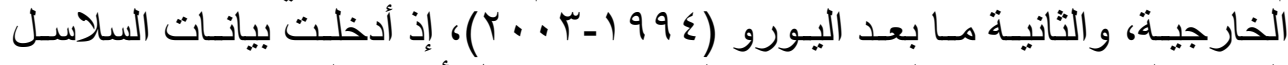

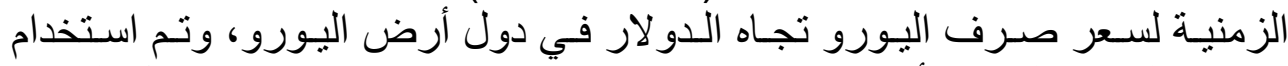

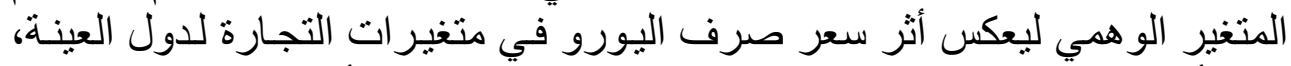

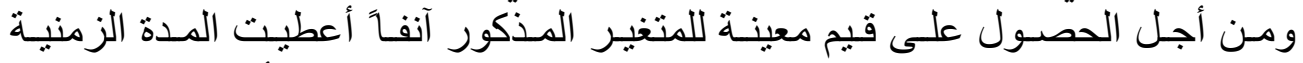

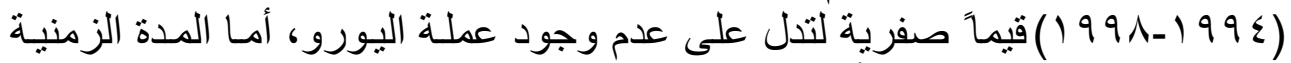

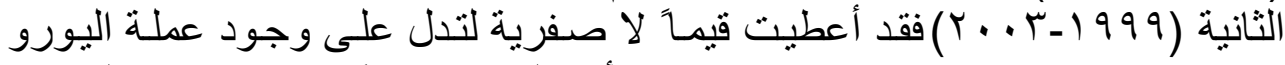

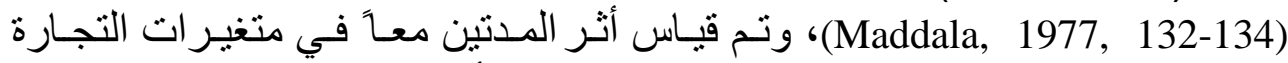

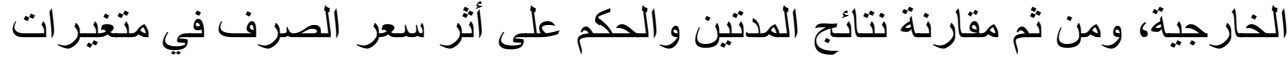

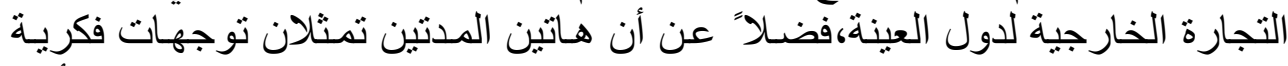

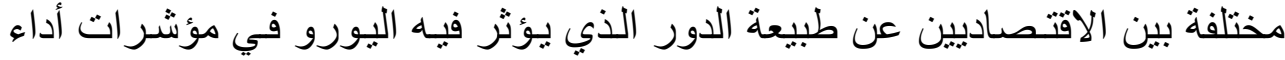

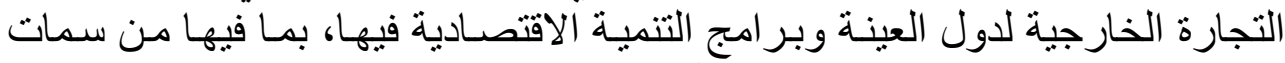

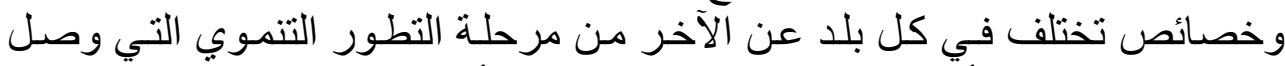

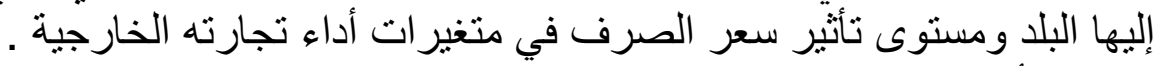

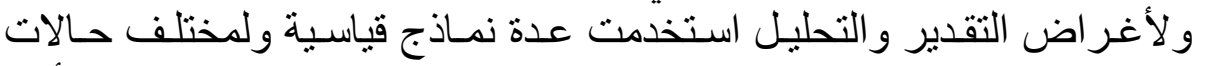

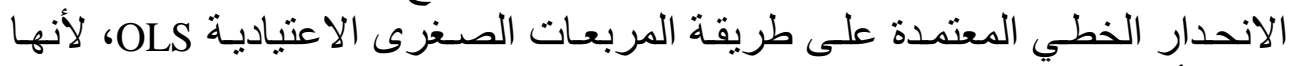

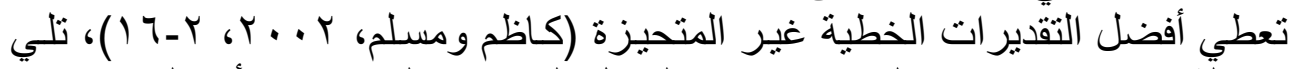

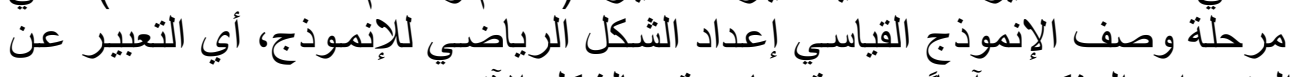

$$
\mathrm{Y}=\mathrm{f}\left(\mathrm{X}_{1}\right)
$$

المتغير ات المذكورة آنفاً بصيغة رياضية إعية وبالثكل الآتي:

وبذلك يمكن صياغة العلافة الموضحة آنفاً بصيغة إنموذج قياسي يأخذ الشكل

$$
\mathrm{Y}_{\mathrm{i}}=\mathrm{B}_{0}+\mathrm{B}_{1} \mathrm{X}_{1}+\mathrm{U}_{\mathrm{i}}
$$

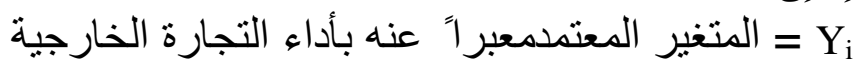


= B B B $_{0}$

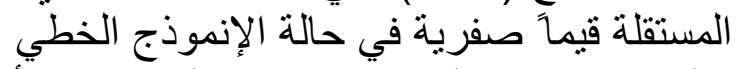

=B1

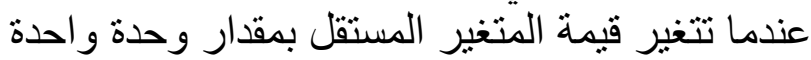

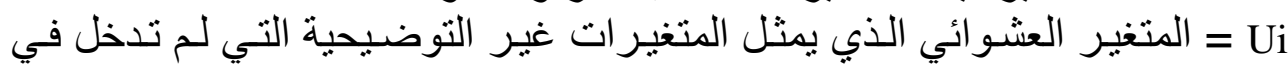
الإنموذج المنغير

$\mathrm{i}=1,2,3, \ldots, \mathrm{n}$

$\mathrm{K}=0,1,2,3, \ldots \ldots \ldots$

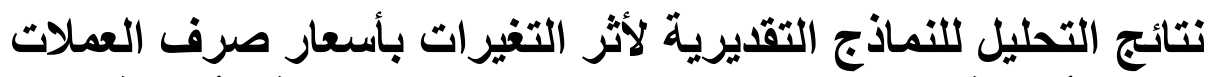

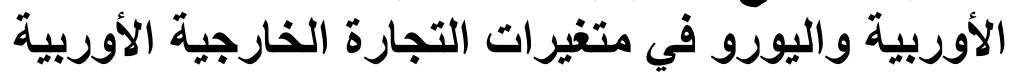

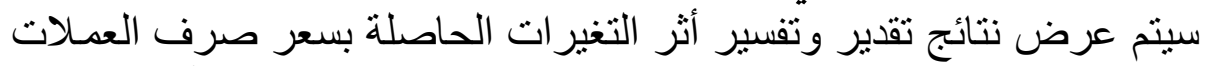
الأوربية واليورو في متغير ات التجارة الخارجية لدول التير العينة وبالثكل الآتي:

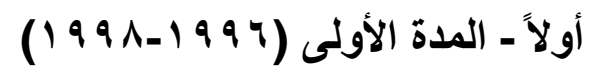

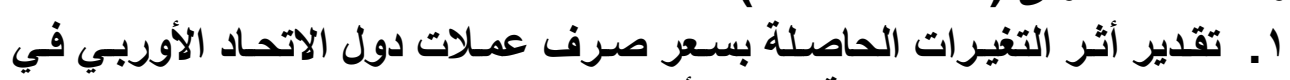

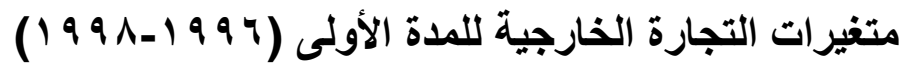

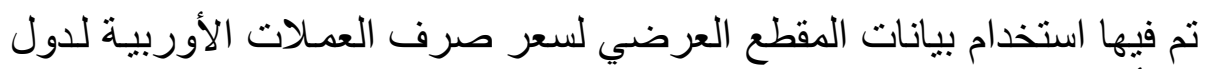

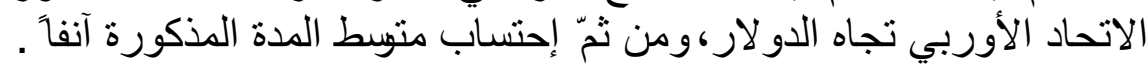
آ. أثر أسعار صرف العملات الأوربية في الأهمية النسبية للصـادرات إلى النى النـاتج لتقدير أثز أسعار صرف العملي العملات الأوربية لدول الاتحاد الأوربي في الأهمية

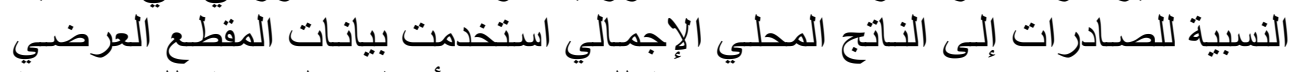

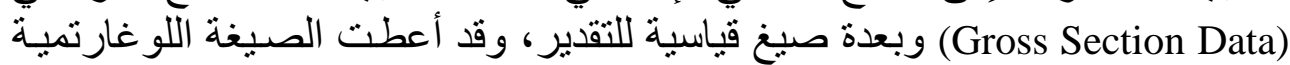
المزدوجة أفضل النتائج و وي على النحو الآتي : $\log \mathrm{Y}_{1}=3.81-0.137 \log \mathrm{X}_{1}$

$\left(\mathrm{t}^{*}\right)=(19.01)(-2.37)$

$\mathrm{R}^{2}=30 \% \quad \mathrm{~F}=5.64 \quad$ D. $\mathrm{W}=1.32$

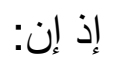
الأهمية النسبية للصادر ات إلى الناتج المحلي الإجمالي. = Y = X

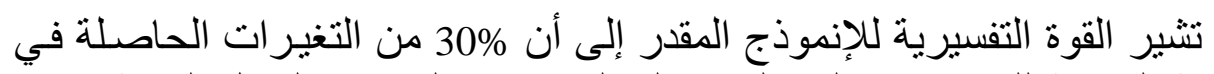

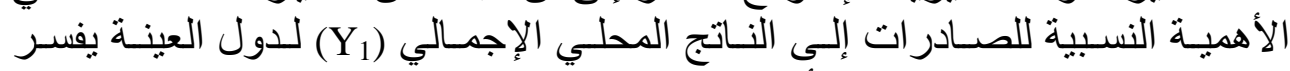

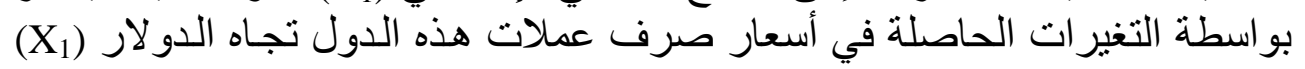




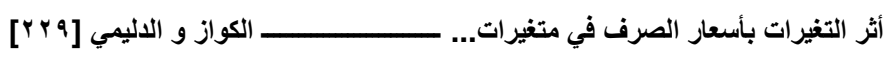

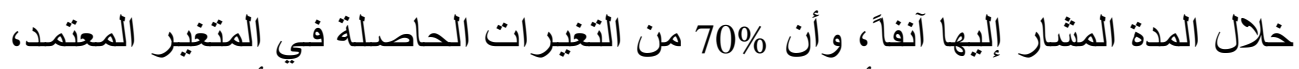

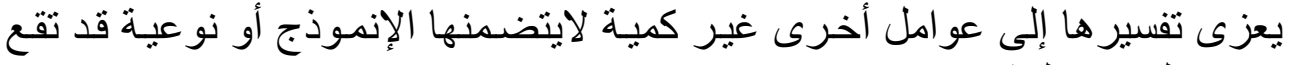
ضمن المتغير العثو ائي.

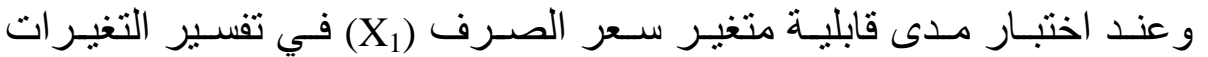

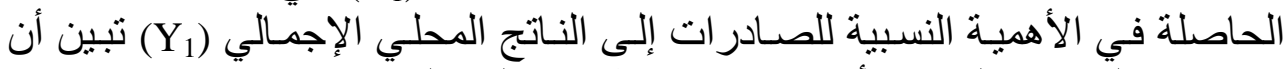

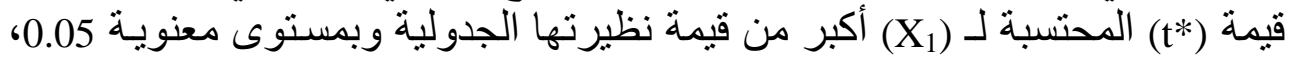

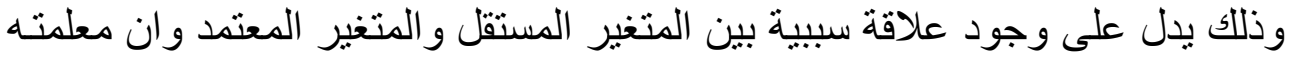

المقدرة ذات معنوية إحصائية وقيمتها تختلف عن الصفر وتساوي الفئ القيمة المقدرة.

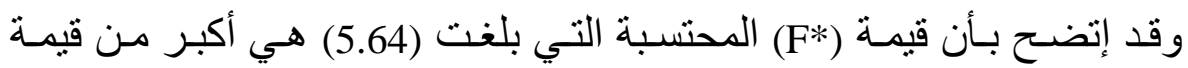

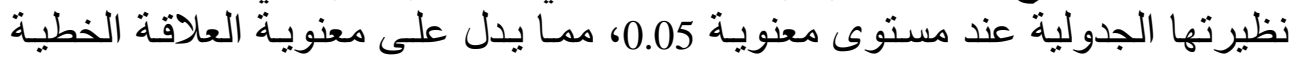

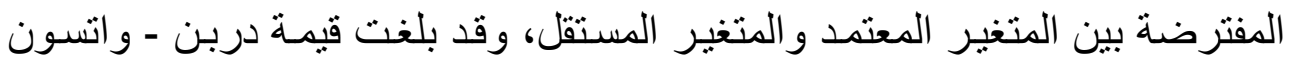

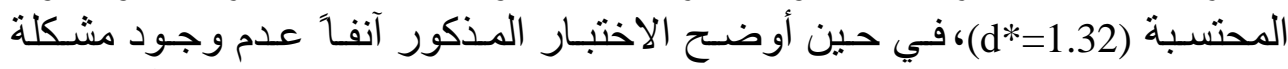

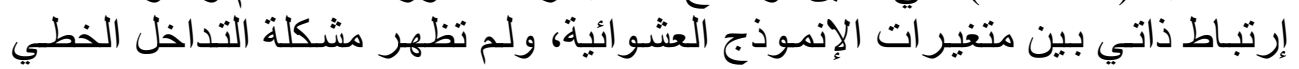
المتعدد في الإنموذج المقدر بكونه يضم متغير مستقل واحد فقط الئ.

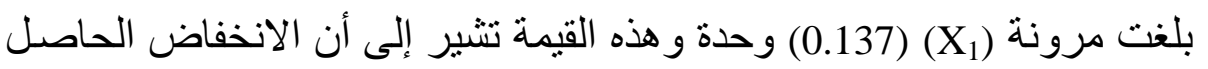

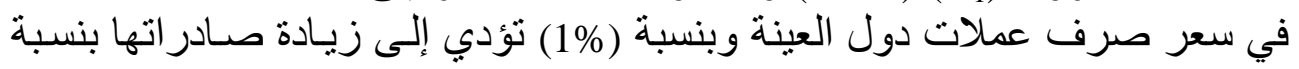

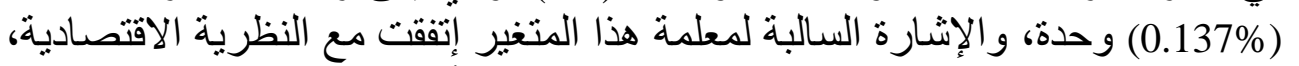

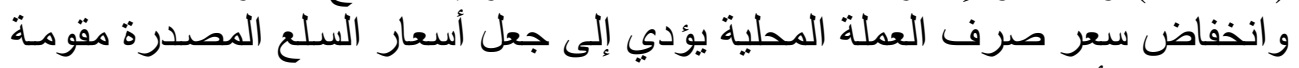

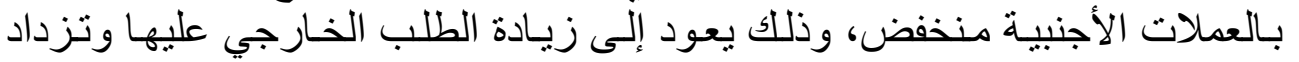

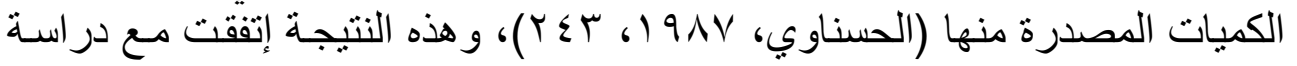

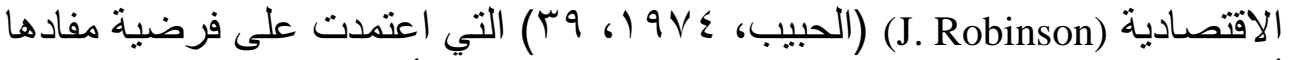

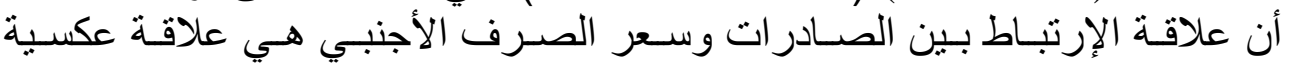

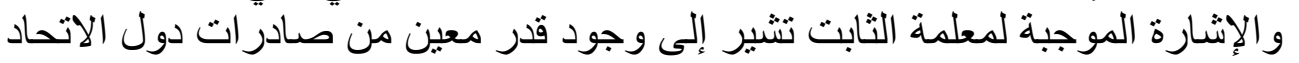

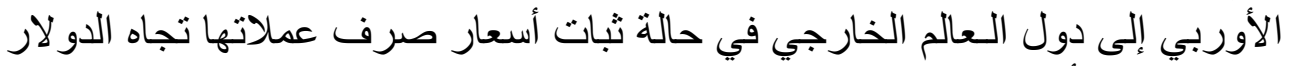

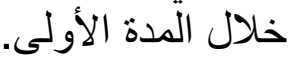
ب. أثر التغيرات الحاصلة في سعر صرف عملات دول الاتحاد الأوربي في الأهمية النسبية للإستير ادات إلى ألناتج المحلي التيع الإجمالي

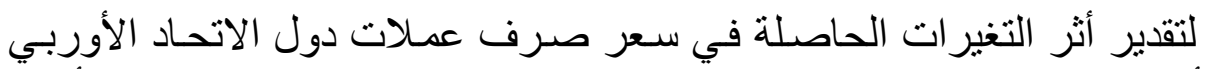

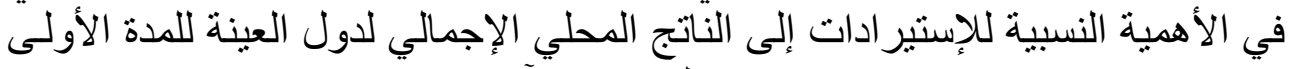

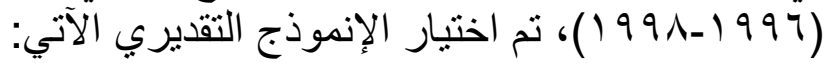
$\log \mathrm{Y}_{2}=3.66-0.079 \log \mathrm{X}_{1}$
$\left(\mathrm{t}^{*}\right)=(19.99)$
$\mathrm{R}^{2}=14 \% \quad \mathrm{~F}=2.27 \quad \mathrm{D} . \mathrm{W}=1.18$

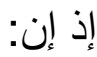
= الأهمية النسبية للإستير ادات إلى الناتج المحلي الإجمالي. = أسعار الصرف الاسمية للعملات الأوربية مقابل الدولار. 
تشير القوة التفسيرية للإنموذج المقدر إلى أن 14\% من التغيرات الحاصلة في

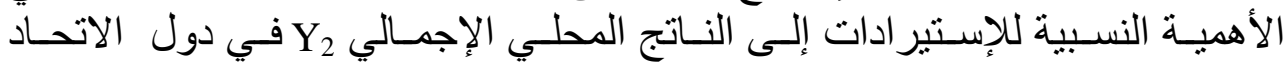

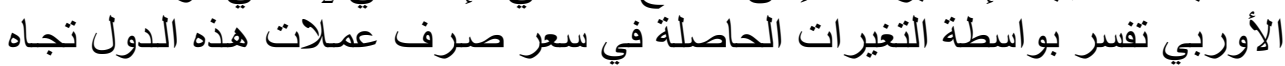
الدولار (X1) خلال المدة ما قبل اليورو.

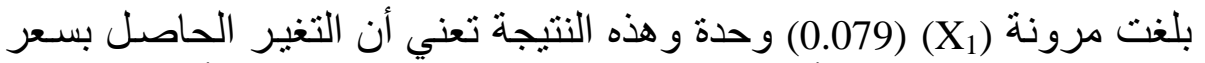

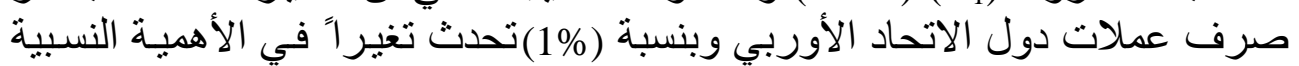

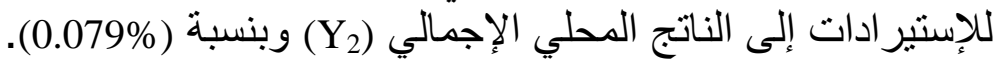

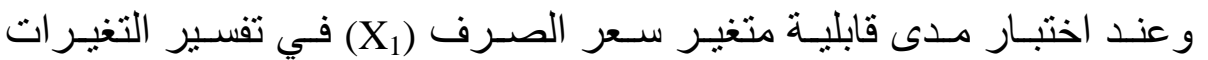

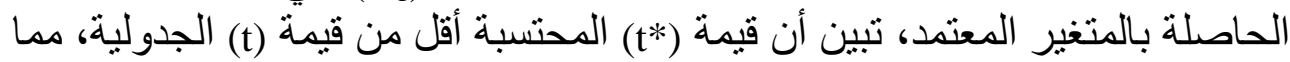

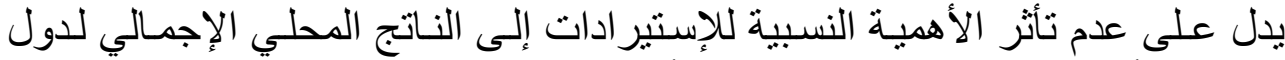
الاتحاد الأوربي بالتغير ات الحاصلة في أسعار صرف الته عملاتها.

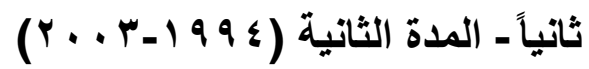

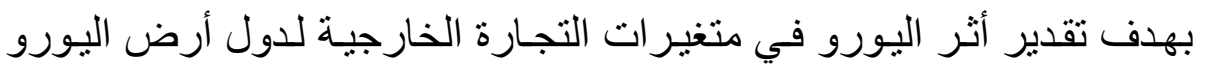

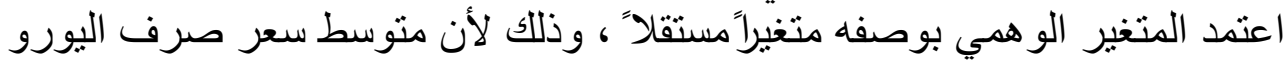

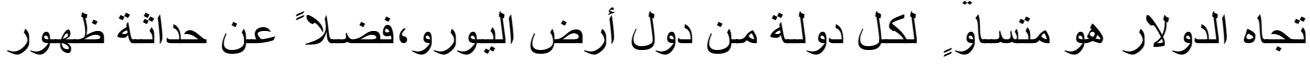

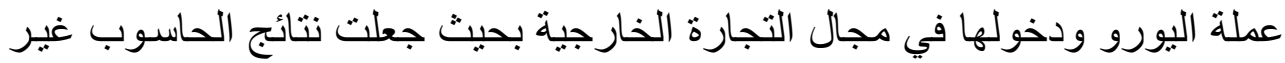

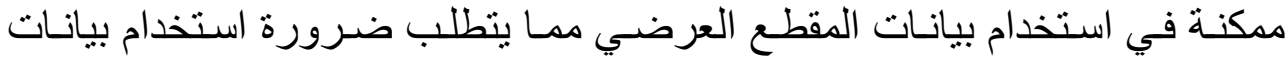

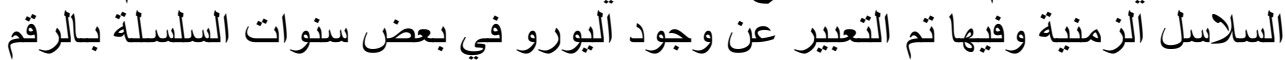

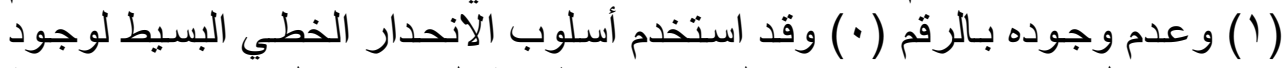

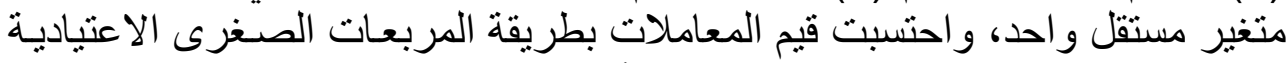

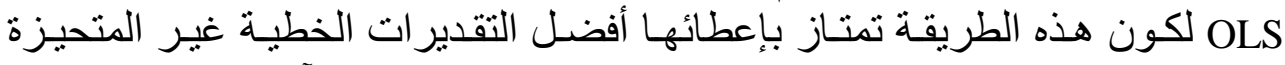
(Koutsyiannis, 1977, 130). وكانت نتائج القياس على النى النحو الآتي:

1

لتقدير أثر سعر صرف اليورو في متغير ات التجارة الخارجية لألمانيا أوضحت نماذج التقدير النتائج الآتية:

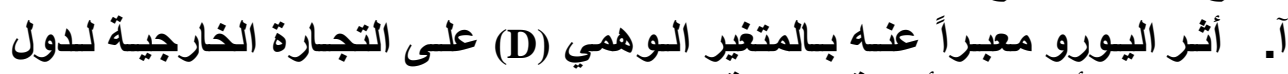

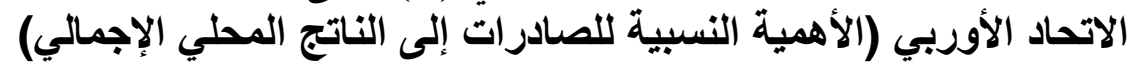

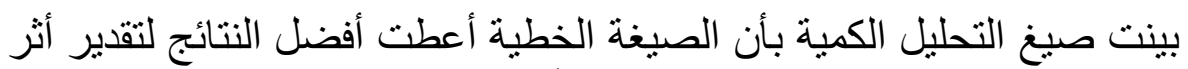

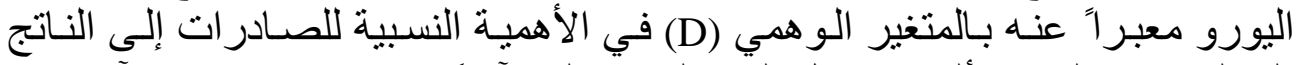

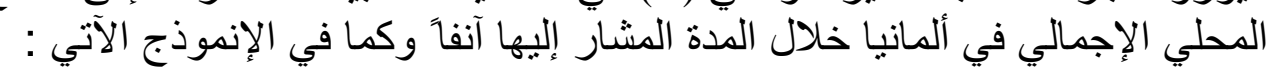
= الأهمية النسبية للصادر ات إلى الناتج المحلي الإجمالي

$\mathrm{Y}^{1}=22.6+6.60 \mathrm{D}$ المتغير الوهي (سعر صرف اليوريه = D

$\left(\mathrm{t}^{*}\right)=(28.03)(5.79)$ 


$$
\text { R أثر التغيرات بأسعار الصرف في متغيرات... ـ }
$$

توضح القوة التفسيرية للإنموذج المقدر إلى أن

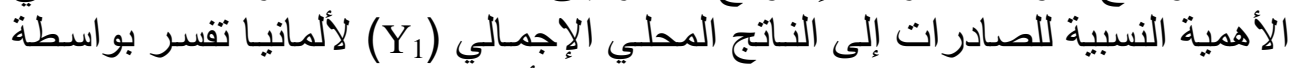

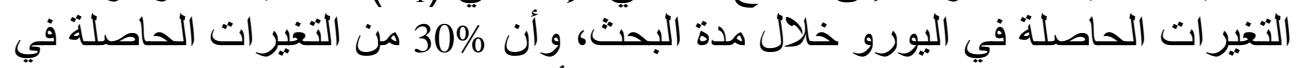

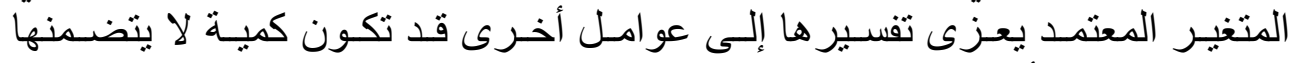
الإنموذج المقدر أو تكون نوعزيه قد تقع ضدمن مفهوم المتغير العشو ائي.

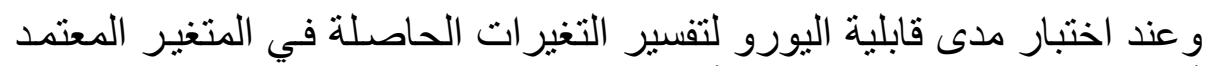

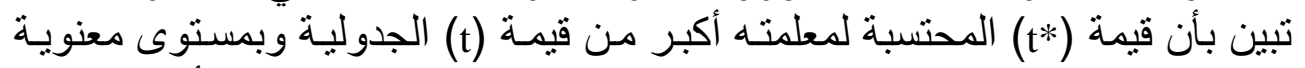

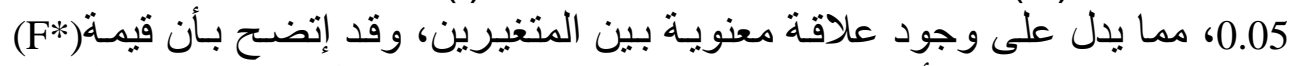

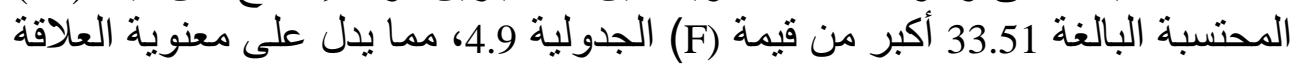

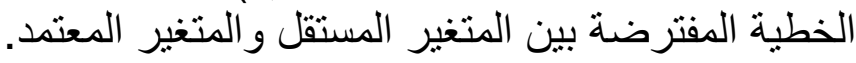

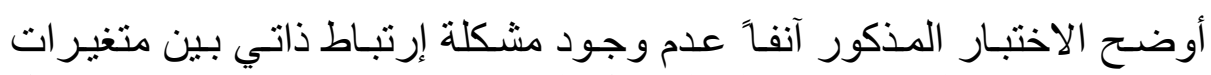

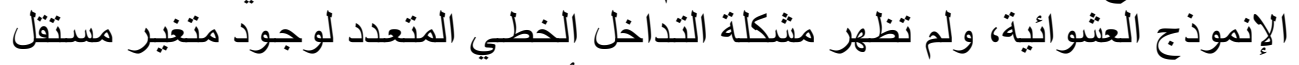

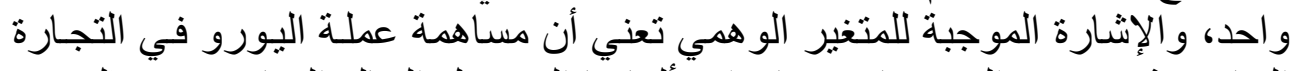

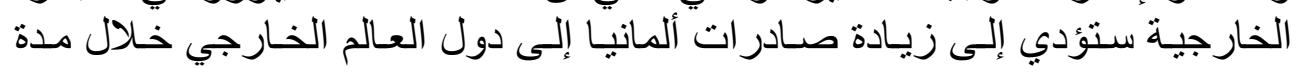
البحث.

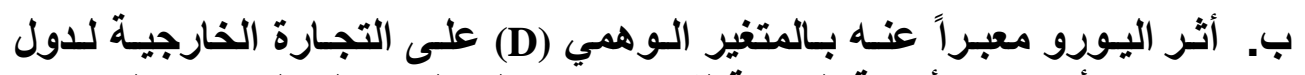

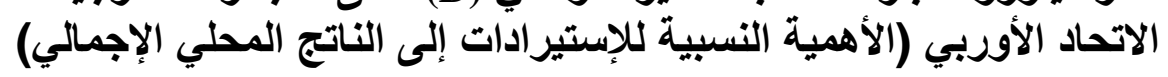

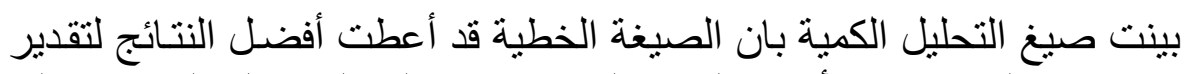

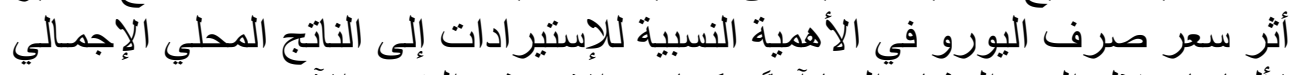

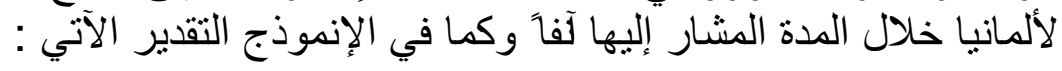
الأهمية النسبية للإستير ادات إلى الناتج المحلي الإجمالي . Y2

$$
\begin{aligned}
& \mathrm{Y}_{2}=20.0+5.80 \mathrm{D} \\
& \left(\mathrm{t}^{*}\right)=(32.88)(6.74) \\
& \mathrm{R}^{2}=85 \% \\
& \mathrm{~F}=45.46 \quad \mathrm{D}-\mathrm{W}=1.41
\end{aligned}
$$

$$
\text { = D المتغير الوهمي (سعر صرف اليورو). }
$$

توضح القوة التفسيرية للإنموذج المقدر بـأن 85\% من التغيرات الحاصلة في الأهمية النسبية للإستير ادات إلى الناتج المحلي الإجمالي (Y

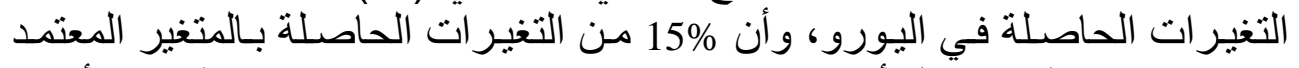

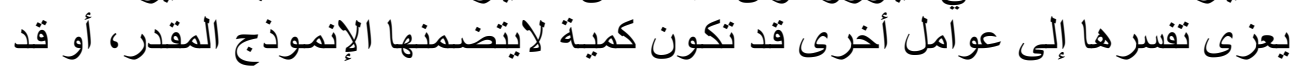

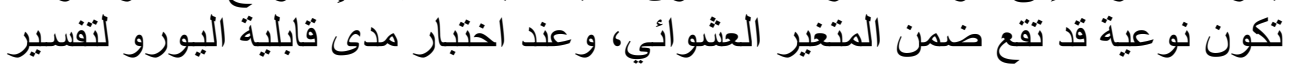




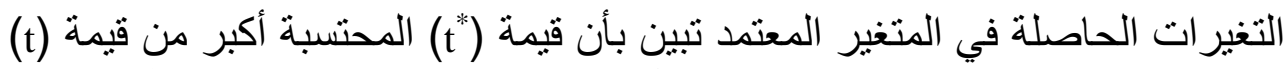

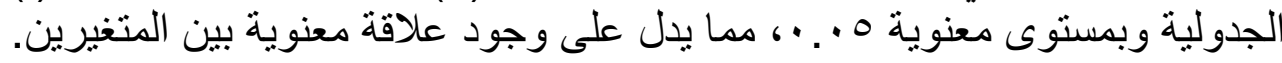

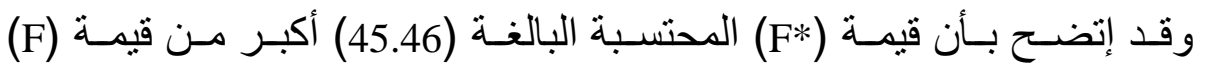

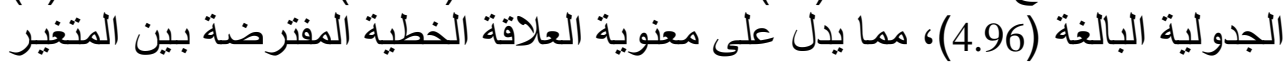

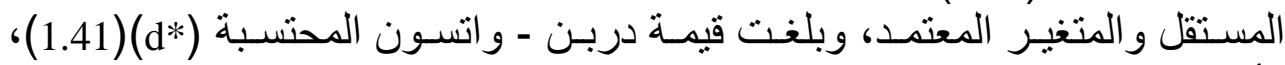

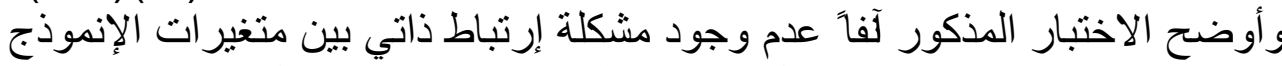

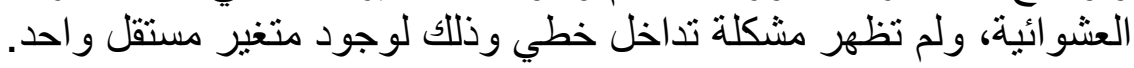

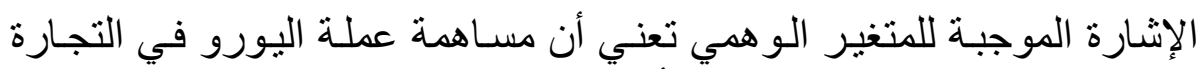

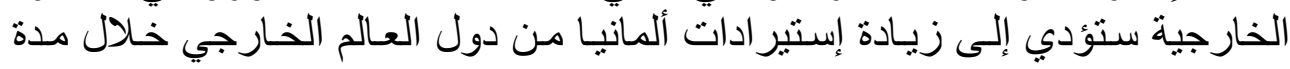


لتقدير أثر اليورو في متغيرات أداء التجارة الخارجية لفرنسا أوضحت النمـاذج القياسية النتائج الآتية:

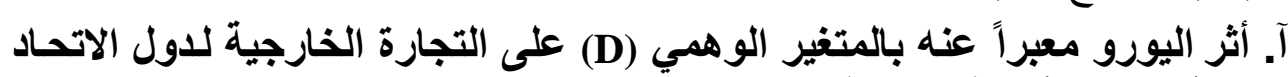

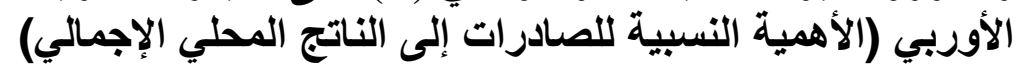

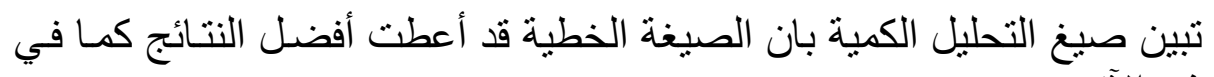

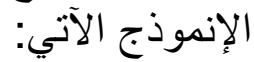
= الأهمية النسبية للصادر ات إلى الناتج المحلي الإجمالي = D $\mathrm{Y}_{1}=17.4+5.40 \mathrm{D}$

$\left(\mathrm{t}^{*}\right)=(44.93)(9.86)$
$\mathrm{R}^{2}=92 \%$
$F=97.20$
D. $\mathrm{W}=1.66$

تشير القوة التفسيرية للإنموذج المقدر إلى أن $92 \%$ من التغيرات الحاصلة في

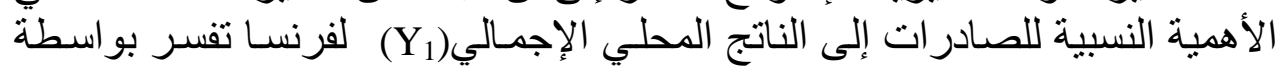

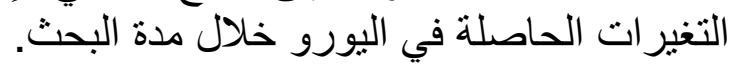

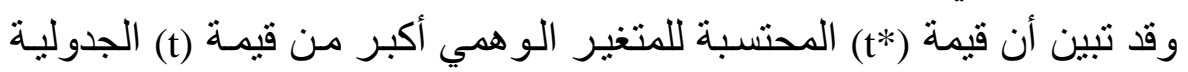
وبذات المستوى السابق للمعنوية، مما يدل على وجود على علاقة سبيية بين المتغيرين.

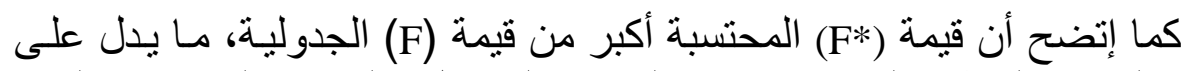

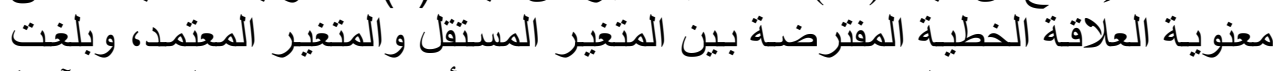

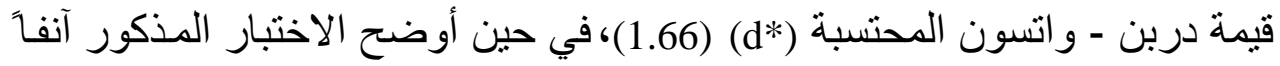

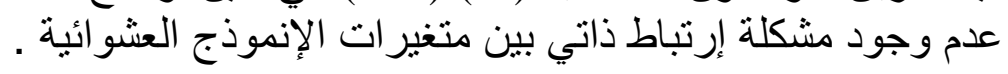

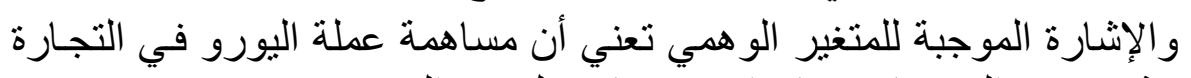

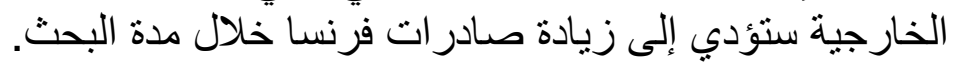

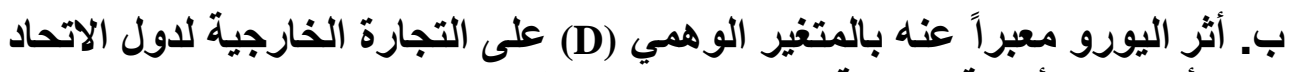

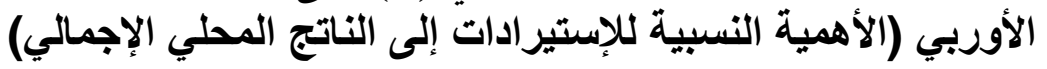

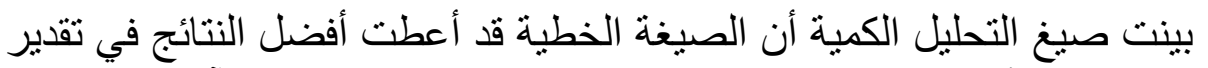

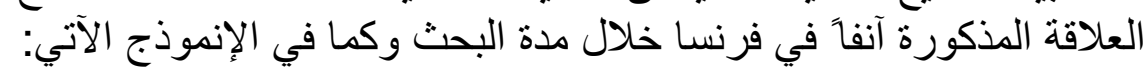

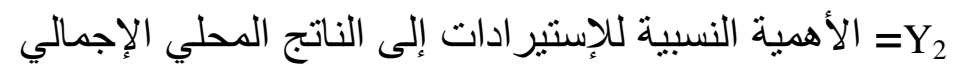

$\mathrm{Y}_{2}=16.8+5.60 \mathrm{D}$ =D المتغير الوهمي (سعر صرف اليورو). D $\left(\mathrm{t}^{*}\right)=(43.38)(10.22)$
$\mathrm{R}^{2}=92 \%$
$F=104.53$
D. $\mathrm{W}=2.43$ 
تبـين القـوة التفسيرية للإنمـوذج المقدر أن 92\% مـن التغيـرات الحاصـلة في الإسي

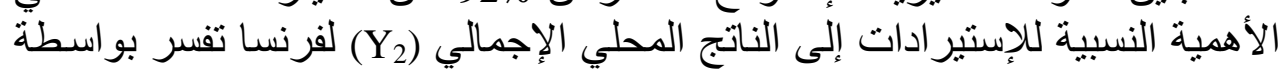
التغيرات الحاصلة في اليورو خلال مدة البحث.

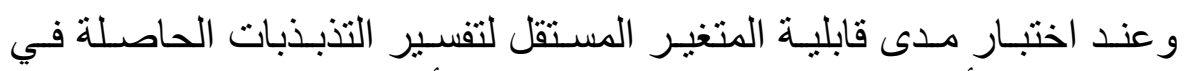

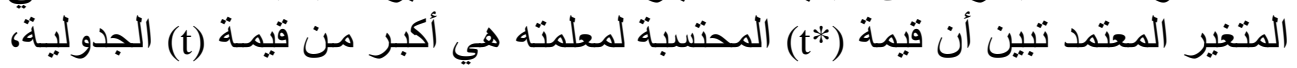

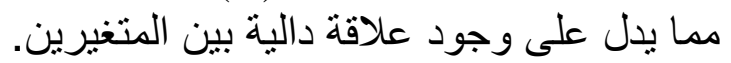

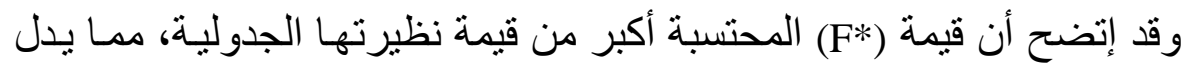
على معنوية العلاقة الخطية المفترضة أنة بين المتغيرين. ولم تظهر مشكلة إرتباط ذاتي بين متغير ات الإنموذج العشو ائية حسب اختبة اختبار

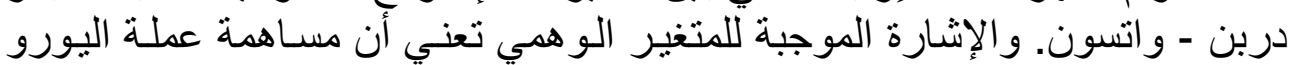

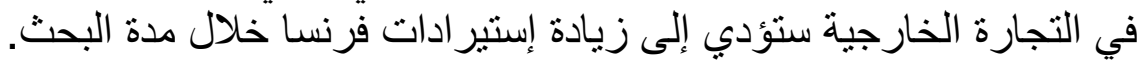

\section{أولاً - الاستتناجات}

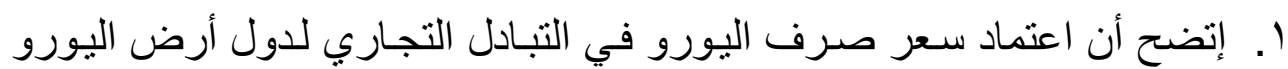

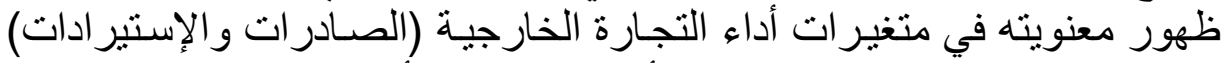

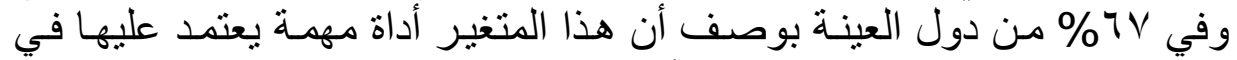
التجارة الخارجية لهذه الدول، وتبين أن سياسة الاعتماد على سعر صرف صرف اليورو

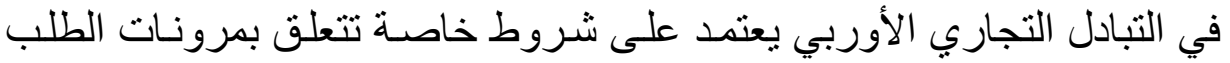

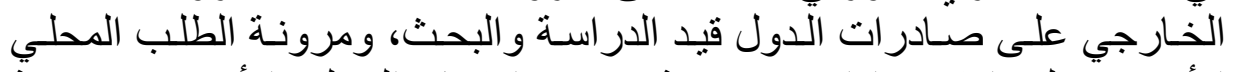

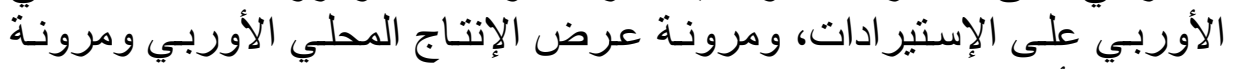
العرض الأجنبي للإستير ادات.

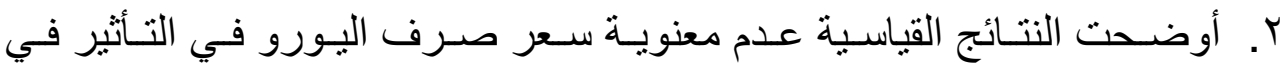

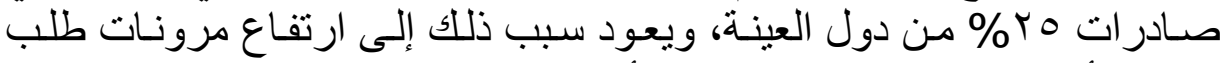

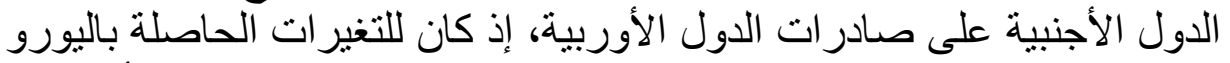

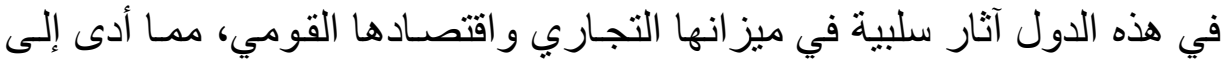

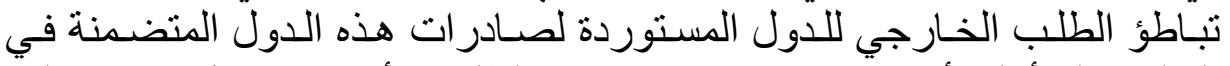

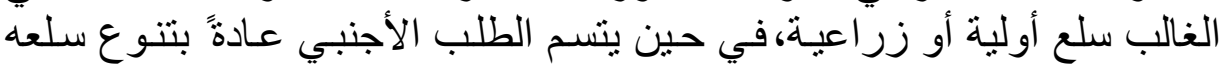
التي تعتمد على مرونة الطلب البة الدخلية .

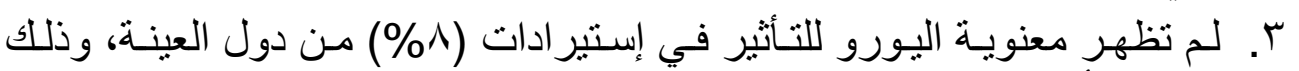

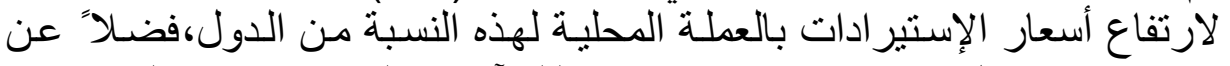

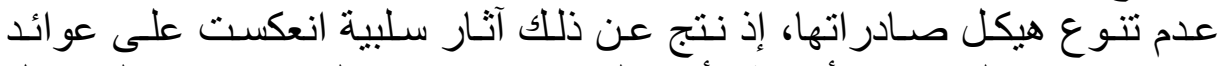

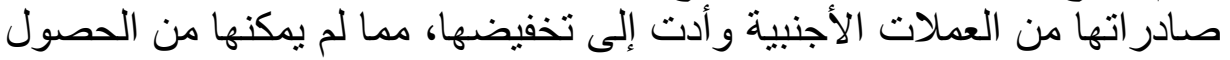
على القدر الكافي من السلع المستوردة حتى لو غيرت من أسعار صرف الإف عملاتها مقابل العملات الأجنبية . 


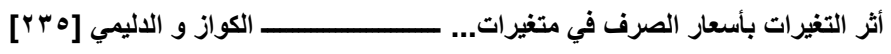

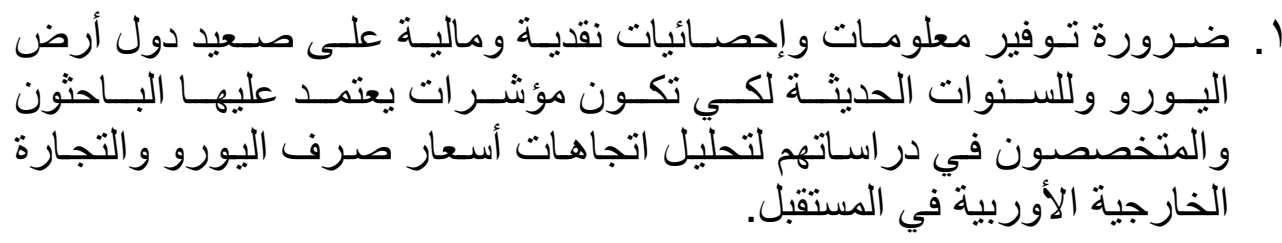

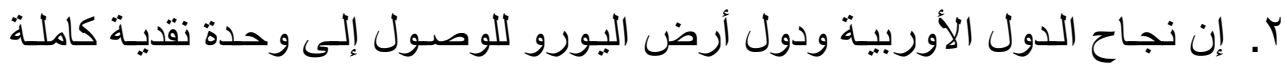

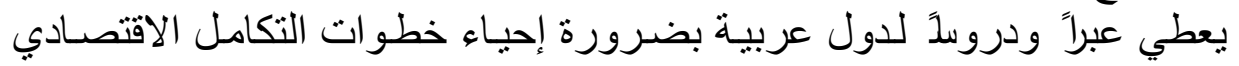

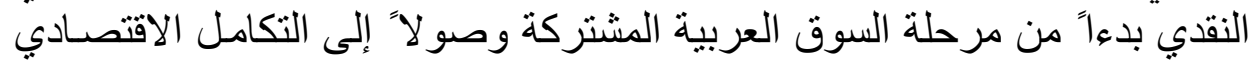
العربي.

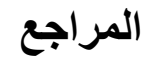
أولاً - المراجع باللغة العز العربية
ا. أموري هادي كاظم وباسم شليبة مسلم، القياس الاقتصادية المادية المتقدم النظرية و التطبيق، مكتبة دنيا

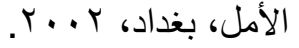

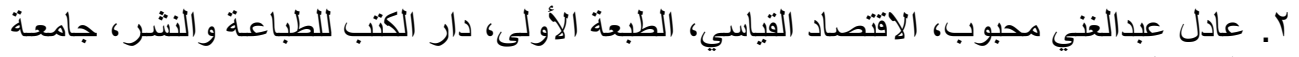

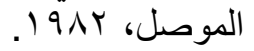
r. عبدالرحمن الحبيب، نظريـة التجـارة الدولية و التكتلات الاقتصـادية، معهد البحوث و الدراسـات

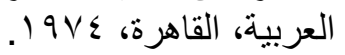

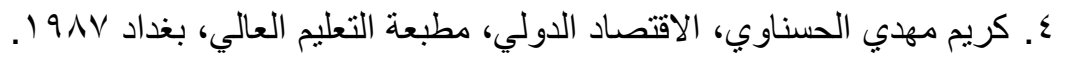

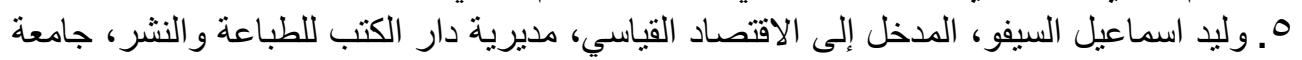

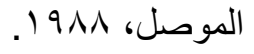

\section{ثانياً - المراجع باللغة الإنكليزية}

1. A. Koutsoyiannis, Theory of Econometrics, Second Edition Macmillan, London, 1977.

2. Alphac C. Chang, Fundamental of Mathematical Economics, Third Edition, McGrawHill, Singapore, 1984.

3. G.S Maddala, Econometrics, International Editions McGraw-Hill, Singapor, 1977.

4. James Riedal, The Demand for LDCS Exports of manufactures: Estimates from HongKong, The Economic Journal, vol. 89, No. 389, London, 1988.

5. Teuku Rahmatsyah and others, Exchange Rate volatility, Trade and fixing for life in Thailand, www. adelaide. Edu. au/cies/0212, pdf, 2002. 